\title{
Computed Tomography Angiography Compared to Catheter Based Angiography in Evaluation of Cerebral Arterial Aneurysm and Arteriovenous Malformation
}

\author{
Sahar M. Badr'1, Zuber Ahmed1, Maway A. Khafaji², Khalid G. H. Alsafi², Hanan Y. Abbas', \\ Saddig D. Jastaniah ${ }^{*}$ \\ ${ }^{1}$ Department of Diagnostic Radiology, Faculty of Applied Medical Sciences, King Abdulaziz University, Jeddah, \\ KSA \\ ${ }^{2}$ Department of Radiology, School of Medicine, King Abdulaziz University, Jeddah, KSA \\ Email: ${ }^{*}$ sjastaniah@kau.edu.sa
}

Received 23 June 2014; revised 22 July 2014; accepted 22 August 2014

Copyright (C) 2014 by authors and Scientific Research Publishing Inc.

This work is licensed under the Creative Commons Attribution International License (CC BY).

http://creativecommons.org/licenses/by/4.0/

c) (i) Open Access

\section{Abstract}

Both cerebral arterial aneurysm and arteriovenous malformation are cerebrovascular disease, which required immediate diagnosis and urgent treatment. Since the introduction of multislice CT scanners, CT angiography (CTA) has become a powerful tool for imaging the vascular system. The goal of this study is to compare catheter based angiography and CTA in the evaluation of cerebral arterial aneurysm and arteriovenous malformation AVM. A retrospective analysis of 50 patients for exploring the record of patient who underwent both multislice CT angiography (MSCTA) and catheter based angiography before treatment is presented during last one year in the department of Radiology, King Fahd Hospital-Jeddah, Kingdom of Saudi Arabia. The sensitivity of CTA for picking up aneurysm is $86 \%$ and the sensitivity of catheter based angiography for picking up aneurysm is $\mathbf{9 7 \%}$. The specificity of CTA for picking up aneurysm is $(76 \%)$, the false positive cases are $(3 \%)$ and the false negative cases are $10 \%$. The sensitivity of both CTA and catheter based angiography for picking up arteriovenous malformation is $(\mathbf{9 0 \% )}$ ). The specificity of CTA for picking up AVM is (76\%), the false positive cases are $(10 \%)$ and no false negative cases in CTA are found. The sensitivity and specificity of catheter based angiography is $100 \%$ in diagnosis and detection of cerebral arterial aneurysm and AVM. The present study concluded that CTA has high sensitivity and specificity in detecting aneurysm and AVM enough to be chosen as the first step. Catheter based angiography, still a gold standard for radiology examination, is the most accurate, sensitive and specific method in diagnosis and detection of cerebral arterial aneurysm and arteriovenous

\footnotetext{
"Corresponding author.
} 
malformation, which can be done as the second step. In addition, catheter based angiography is done for treatment planning, treatment with interventional procedure and for prognosis after treatment.

\author{
Keywords \\ CTA, CCA, Cerebral Arterial Aneurysm and Arteriovenous Malformation
}

\title{
1. Introduction
}

Both cerebral arterial aneurysm and arteriovenous malformation are cerebrovascular disease, which required immediate diagnosis and urgent treatment [1].

Subarachnoid hemorrhage occurred spontaneously from a ruptured cerebral aneurysm, or may result from head injury. In general, the diagnosis is confirmed with a CT scan of the head, or occasionally by lumbar puncture. CT scan without contrast, of the brain which identifies over 95 percent of cases especially is the modality of choice on the first day after the onset of bleeding. MRI may be more sensitive than CT after several days [2]. Within six hours of the onset of symptoms a single study has reported that CT is 100 percent sensitive.

The CT angiography has advantages i.e. enhanced imaging of the aneurysm neck, detection of aneurysms up to $1.7 \mathrm{~mm}$ and superior delineation of surgical anatomy. On the other hand, some disadvantages of CT angiography are worth mentioning such as inefficient detection and delineation of cavernous sinus and posterior inferior cerebellar artery and radiation risks [3] [4].

During the treatment of patients having intracranial aneurysms and specifically in the evaluation of patients suffering from painful partial cranial nerve III palsy to rule out posterior communicating artery aneurysms [5]. Moreover, other studies have proven that a 7-mm posterior communicating artery aneurysm can be missed by MR imaging of the brain similarly in case of MR angiography, but could be observed by CT angiography [6] [7]. Furthermore, it has been shown that CT angiography was better in detecting traumatic aneurysms in patients with skull base fractures [8]. It seems that newer machines have increased in resolution enough to reliably detect aneurysms as small as $3 \mathrm{~mm}$.

The goal of this study is to compare catheter based angiography and CTA in the evaluation of cerebral arterial aneurysm and arteriovenous malformation.

\section{Material and Method}

This is a retrospective study for exploring the record of patients who have underwent both CTA and catheter based angiography during last one year in the Radiology Department; King Fahd Hospital-Jeddah, Kingdom of Saudi Arabia. The cases included in study have been imaged with both modalities for the diagnosis of cerebral arterial aneurysm and AVM.

In our study, 50 patients (32 male and 18 female), aged (12 - 65 year) with subarachnoid hemorrhage (SAH), intracerebral hemorrhage (ICH) or intraventricular hemorrhage (IVH) detected by non-enhanced cranial CT with suspected arterial aneurysm and AVM who have been imaged first in CTA with MSCT scanner speed light Volume CT (VCT-64 slice, General Electric Company Healthcare), Then in catheter based angiography with DSA artis zee biplane system, Siemens Company. A standardized evaluation was performed by experienced radiologists in both CTA and catheter based angiography.

Demographic data: The details of patients involved in my research are listed in Table 1, Table 2.

\section{Results}

Fifty patient with subarachnoid hemorrhage SAH, ICH or IVH detected by non-enhanced cranial CT, 29 (58\%) of cases have intracerebral arterial aneurysm and 21 (42\%) have AVM. The (58\%) 29 patients with cerebral arterial aneurysm out of which (20\%) 10 female and (38\%) 19 male came with different ages from 3rd to 7th decade, which mean that the aneurysm develops in all ages and the majority in adult between 30 to 60 years. The (42\%) 21 patients with arteriovenous malformation out of which (14\%) 7 female and (28\%) 14 male came with ages from 2nd to 5th decade, as a result the AVM appear more in younger patients between 10 to 30 years (Figure 1, Figure 2). 
Table 1. Represented details of 29 out of 50 patients with SAH, IVH or ICH and suspected aneurysm underwent CTA and catheter based angiography.

\begin{tabular}{|c|c|c|c|c|c|c|}
\hline Patient & Age & Gender & Diagnosis & In CTA & In Angio1 & In Angio2 \\
\hline 1 & 53 & M & SAH & $\mathrm{N}$ & Very small & \\
\hline 2 & 54 & M & SAH-IVH & $\mathrm{Y}$ & $\mathrm{Y}$ & \\
\hline 3 & 56 & $\mathrm{~F}$ & SAH & $\mathrm{Y}$ & Coiling & \\
\hline 4 & 32 & F & SAH & $\mathrm{Y}$ & $\mathrm{Y}$ & Coiling \\
\hline 5 & 54 & F & SAH-ICH & $\mathrm{Y}$ & $\mathrm{Y}$ & Coiling \\
\hline 6 & 35 & F & SAH & $\mathrm{N}$ & Very small & f/u-clip \\
\hline 7 & 37 & M & SAH & $\mathrm{Y}$ & Coiling & \\
\hline 8 & 55 & M & SAH & $\mathrm{N}$ & Very small & \\
\hline 9 & 65 & M & SAH & $\mathrm{Y}$ & $\mathrm{Y}$ & Coiling \\
\hline 10 & 42 & F & SAH & Suspicion & $\mathrm{Y}$ & f/u-clip \\
\hline 11 & 42 & M & SAH-IVH & Suspicion & $\mathrm{Y}$ & \\
\hline 12 & 40 & M & SAH & $\mathrm{Y}$ & Coiling & \\
\hline 13 & 50 & M & SAH & $\mathrm{Y}$ & $\mathrm{Y}$ & Coiling \\
\hline 14 & 38 & F & SAH & Suspicion & $\mathrm{N}$ & \\
\hline 15 & 51 & M & SAH & $\mathrm{Y}$ & $\mathrm{Y}$ & Coiling \\
\hline 16 & 45 & M & SAH & $\mathrm{Y}$ & $\mathrm{Y}$ & Coiling \\
\hline 17 & 55 & M & SAH & $\mathrm{Y}$ & $\mathrm{Y}$ & Coiling \\
\hline 18 & 58 & M & SAH-ICH & $\mathrm{Y}$ & Coiling & \\
\hline 19 & 31 & M & SAH & $\mathrm{Y}$ & $\mathrm{Y}$ & \\
\hline 20 & 60 & F & SAH & $\mathrm{Y}$ & Coiling & \\
\hline 21 & 40 & F & SAH-IVH & Suspicion & $\mathrm{Y}$ & f/u-clip \\
\hline 22 & 49 & M & SAH & $\mathrm{Y}$ & $\mathrm{Y}$ & \\
\hline 23 & 50 & F & SAH & $\mathrm{Y}$ & $\mathrm{Y}$ & Coiling \\
\hline 24 & 33 & M & SAH & $\mathrm{Y}$ & Coiling & \\
\hline 25 & 28 & M & SAH & $\mathrm{Y}$ & $\mathrm{Y}$ & \\
\hline 26 & 35 & M & SAH & $\mathrm{Y}$ & $\mathrm{Y}$ & Coiling \\
\hline 27 & 30 & $\mathrm{~F}$ & SAH & $\mathrm{Y}$ & $\mathrm{Y}$ & Coiling \\
\hline 28 & 25 & $\mathrm{M}$ & SAH & $\mathrm{Y}$ & Coiling & \\
\hline 29 & 40 & M & SAH & $\mathrm{Y}$ & $\mathrm{Y}$ & Coiling \\
\hline
\end{tabular}


Table 2. Represented details of 21 out of 50 patients with SAH, IVH or ICH and suspected arteriovenous malformation underwent CTA and catheter based angiography.

\begin{tabular}{|c|c|c|c|c|c|c|}
\hline Patient & Age & Gender & Diagnosis & In CTA & In Angio1 & In Angio2 \\
\hline 1 & 22 & M & IVH-ICH & Suspicion & $\mathrm{Y}$ & Embolization \\
\hline 2 & 28 & M & $\mathrm{ICH}$ & Suspicion & $\mathrm{Y}$ & Embolization \\
\hline 3 & 29 & F & SAH & $\mathrm{Y}$ & $\mathrm{Y}$ & Embolization \\
\hline 4 & 38 & M & SAH-ICH & $\mathrm{Y}$ & Embolization & $F \backslash U$ \\
\hline 5 & 25 & M & SAH & Suspicion & $\mathrm{N}$ & \\
\hline 6 & 30 & M & SAH & $\mathrm{Y}$ & Embolization & \\
\hline 7 & 14 & F & $\mathrm{ICH}$ & $\mathrm{Y}$ & Embolization & $F \backslash U$ \\
\hline 8 & 38 & M & SAH-ICH & Suspicion & $\mathrm{Y}$ & Embolization \\
\hline 9 & 23 & M & $\mathrm{ICH}$ & $\mathrm{Y}$ & $\mathrm{Y}$ & \\
\hline 10 & 18 & F & SAH & $\mathrm{Y}$ & $\mathrm{Y}$ & Embolization \\
\hline 11 & 20 & M & SAH & $\mathrm{Y}$ & Embolization & \\
\hline 12 & 28 & M & SAH & $\mathrm{Y}$ & Embolization & \\
\hline 13 & 35 & M & SAH & $\mathrm{Y}$ & $\mathrm{Y}$ & Embolization \\
\hline 14 & 19 & $\mathrm{~F}$ & SAH & $\mathrm{Y}$ & $\mathrm{Y}$ & Embolization \\
\hline 15 & 19 & M & SAH & $\mathrm{Y}$ & Embolization & $F \backslash U$ \\
\hline 16 & 12 & M & SAH & $\mathrm{Y}$ & Embolization & \\
\hline 17 & 15 & M & SAH & $\mathrm{Y}$ & Embolization & $F \backslash U$ \\
\hline 18 & 19 & M & SAH & $\mathrm{Y}$ & $\mathrm{Y}$ & Embolization \\
\hline 19 & 23 & F & SAH & $\mathrm{Y}$ & $\mathrm{Y}$ & Embolization \\
\hline 20 & 14 & F & SAH-IVH & Suspicion & $\mathrm{N}$ & \\
\hline 21 & 16 & F & SAH & $\mathrm{Y}$ & $\mathrm{Y}$ & Embolization \\
\hline
\end{tabular}
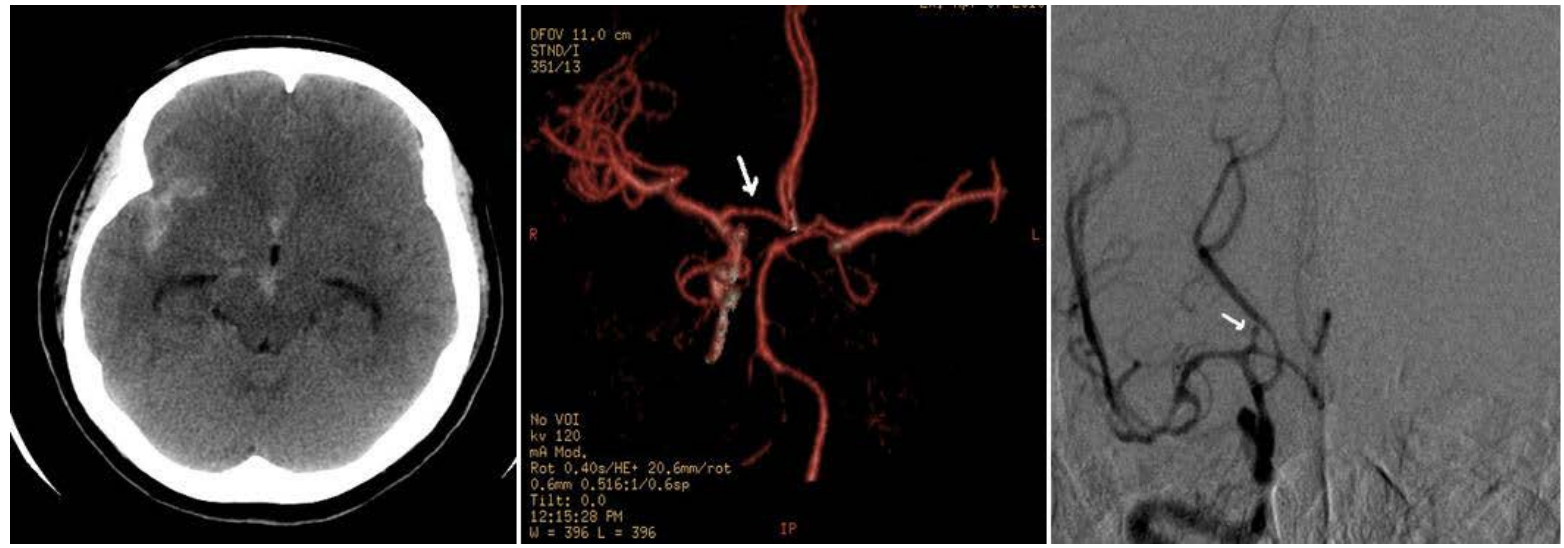

Figure 1. Female patient 35y old with SAH in CTA there is no definite vascular focal out pouching/aneurysm or malformation identified. In catheter based angiography Evidence of very small aneurysm at the A1 segment of the right anterior cerebral artery adjacent to its origin from the carotid bifurcation which protruded superiorly and mildly posteriorly. 
The patient with intracerebral arterial aneurysm came with different ages from 3rd to 7th decade and patient with AVM most of them from 2nd to 4th decade (Figure 3). In CTA 76\% of patient with suspected aneurysm was proved that they have cerebral aneurysm, $14 \%$ suspicion and $10 \%$ with no aneurysm-catheter based angiography is recommended for accurate assessment. In catheter based angiography $97 \%$ was proved that they have cerebral aneurysm and 3\% was proved that they do not have aneurysm (Figure 4). In CTA 76\% of patient with suspected AVM was proved that they have arteriovenous malformation, 24\% suspicion—catheter based angiography is recommended for accurate assessment.

In catheter based angiography $90 \%$ was proved that they have arteriovenous malformation and $10 \%$ was proved that they do not have AVM (Figure 5), the sensitivity of CTA for picking up aneurysm is $86 \%$ and in AVM is $90 \%$. The sensitivity of catheter based angiography for picking up aneurysm and AVM is $100 \%$ (Figure 6).

The specificity of CTA for picking up both aneurysm and AVM is $76 \%$ and the specificity of catheter based angiography for picking up aneurysm and AVM is 100\% (Figure 7), in CTA the false positive cases in aneurysm was 3\% and in AVM was 10\%. The false negative cases in aneurysm was $10 \%$ and in AVM $0 \%$ (Figure 8).
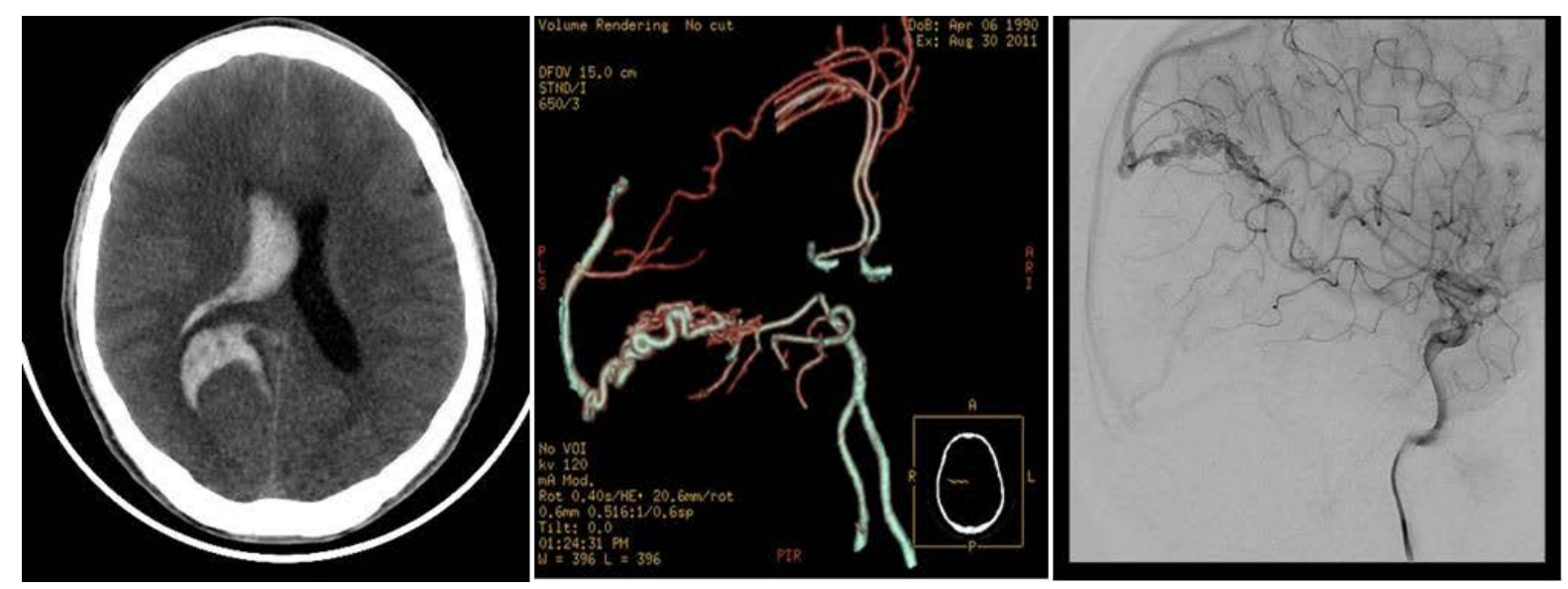

Figure 2. Male patient 21y old with intracerebral hemorrhage and intraventricular hemorrhage, complaining of severe headache. In CTA, enlarged AVM in right posterior cerebral artery and drained in the superior sagittal sinus which conformed by diagnostic catheter based angiography.

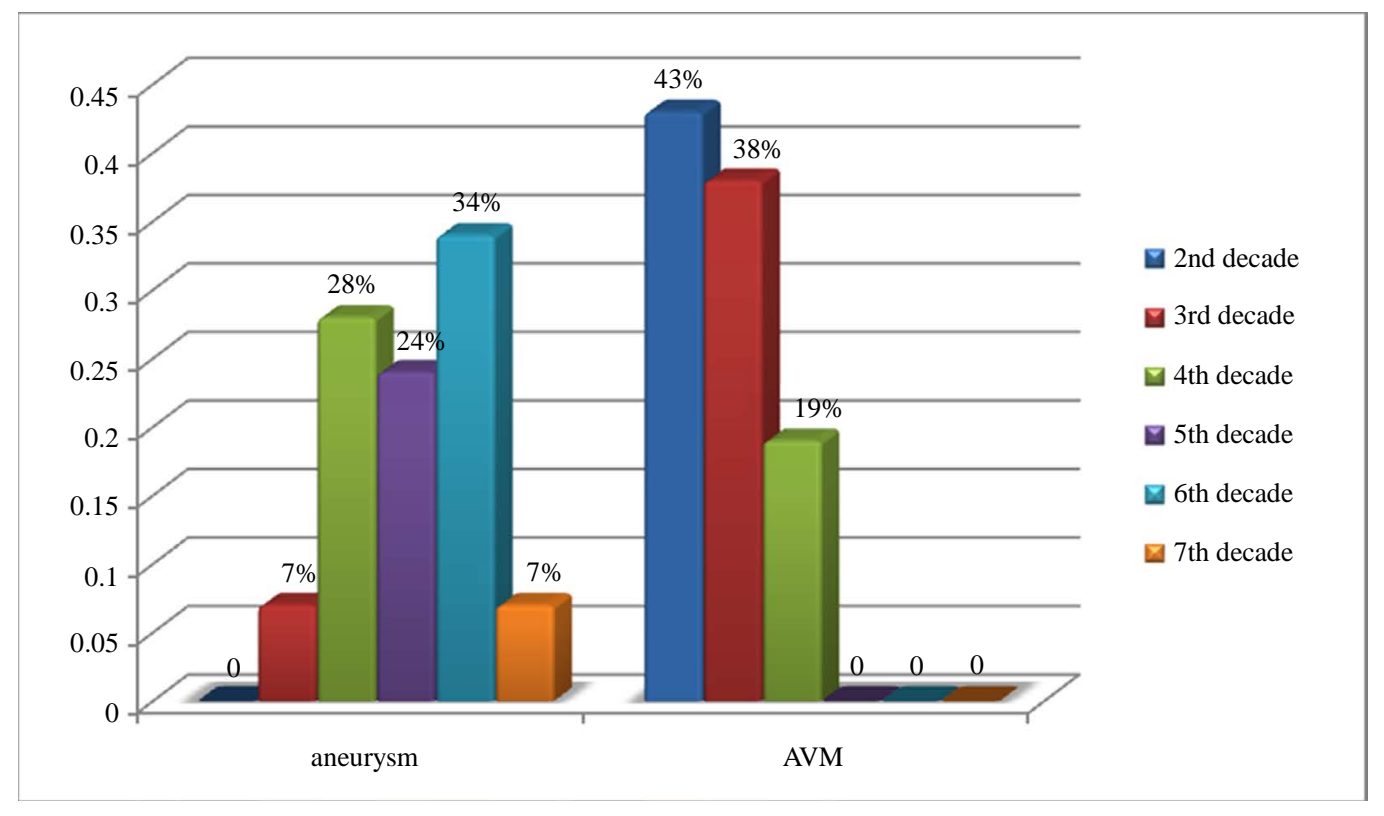

Figure 3. Age distribution of patient with aneurysm and AVM. 


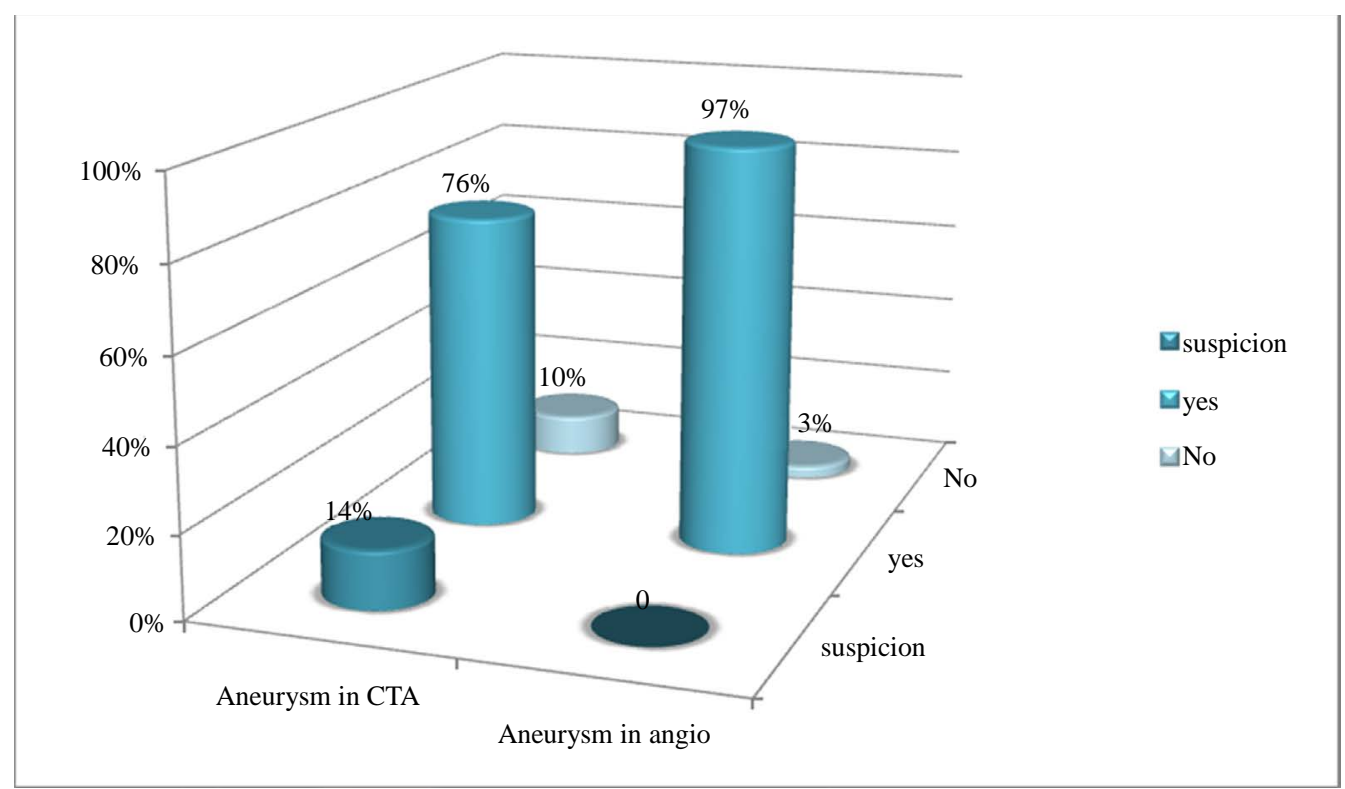

Figure 4. Comparison of the percentage distribution of cases with positive, negative and suspicion of aneurysm.

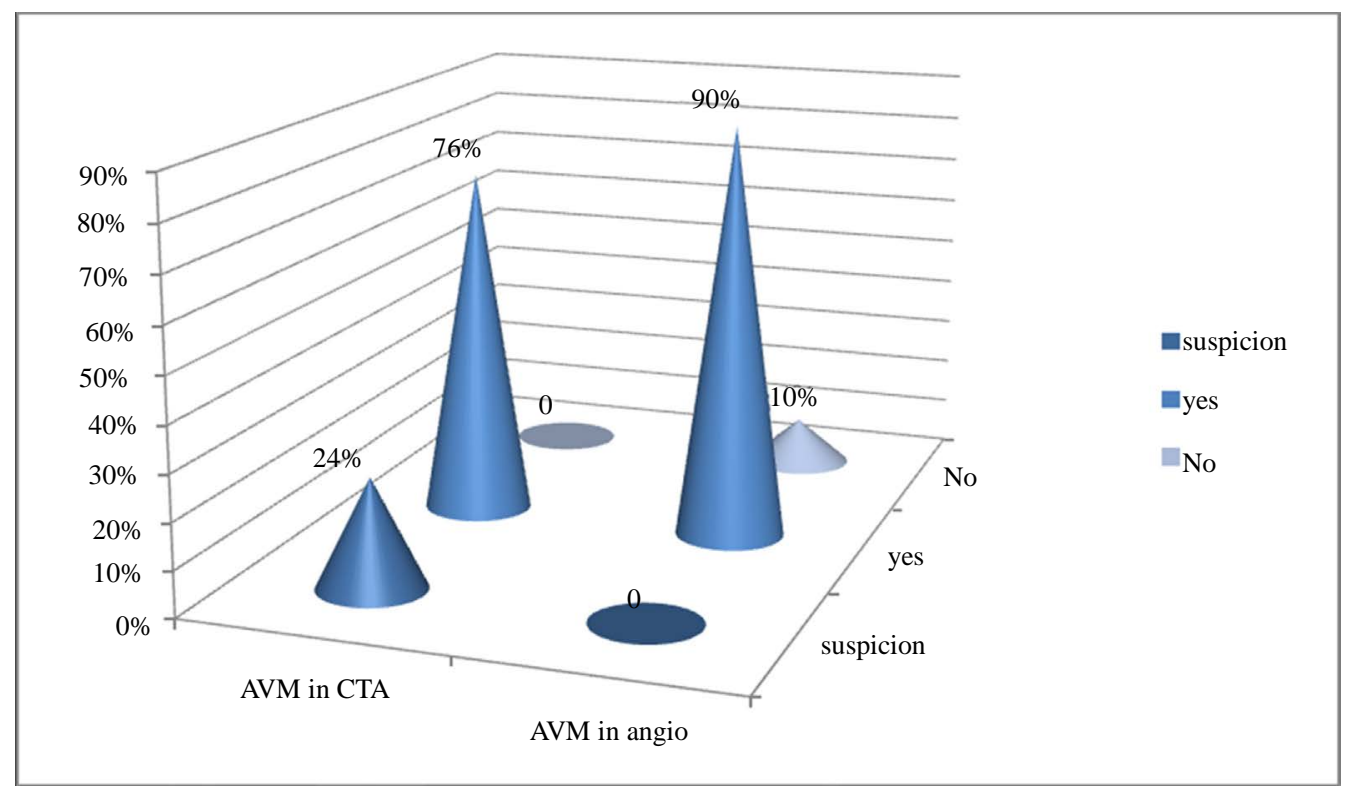

Figure 5. Comparison of the percentage distribution of cases with positive, negative and suspicion of AVM.

The distribution of further workup of cases underwent diagnostic catheter based angiography showed that out of 29 patients with aneurysm, 20 patients underwent catheter based angiography for diagnosis and treatment planning, and 17 patients underwent catheter based angiography for interventional procedure for treatment and 3 patients for follow up angiography after surgery. Out of 21 patients with AVM, 11 patients underwent catheter based angiography for diagnosis and treatment planning, 18 patients underwent catheter based angiography for interventional procedure for treatment and 4 patients for follow up angiography post Embolization.

\section{Discussion}

Most referred patients came with the diagnosis of AVM using conventional catheter angiography (CCA). 


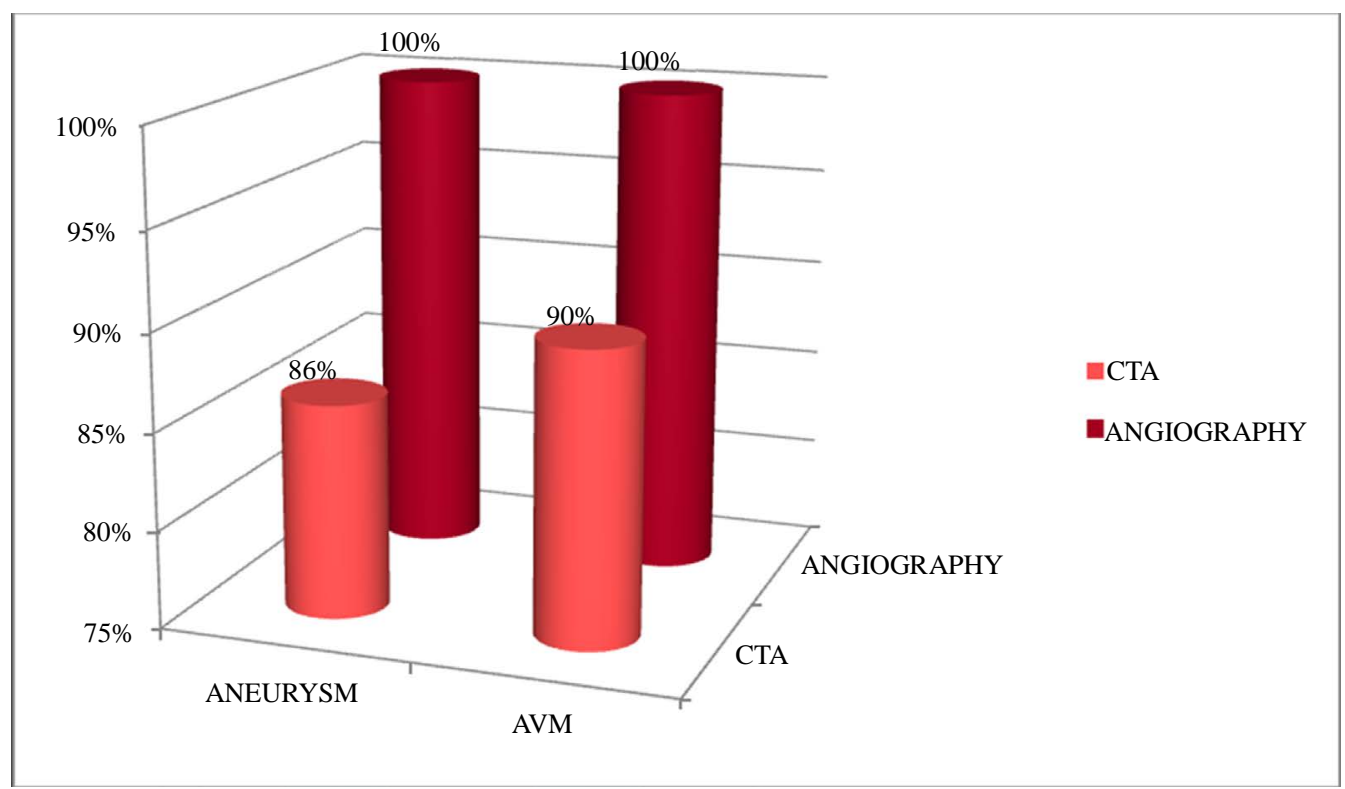

Figure 6. Percentage distribution of the sensitivity for picking up aneurysm and AVM.

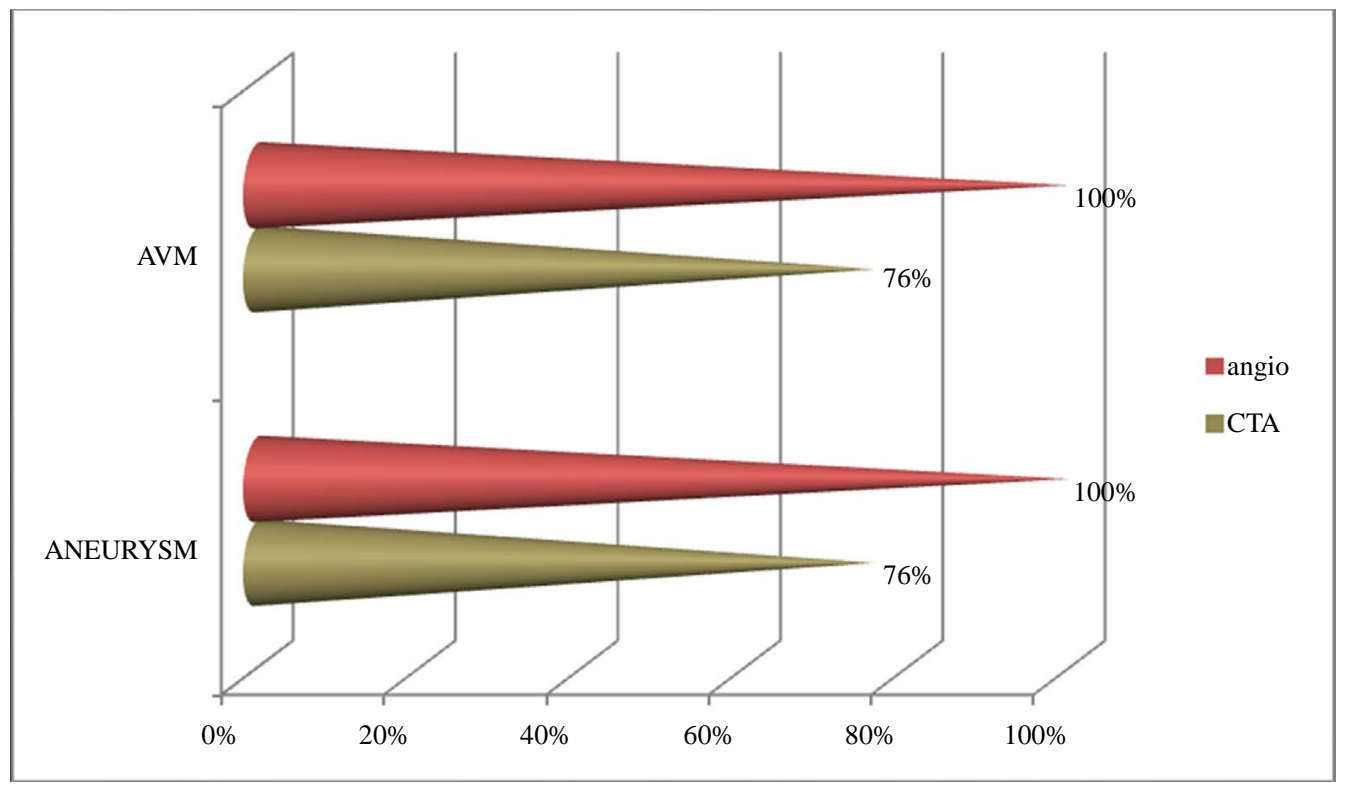

Figure 7. The specificity of CTA for picking up aneurysm and AVM.

Even with limited risk of cerebral angiography in patients with AVMs, the diagnostic accuracy of noninvasive imaging techniques, such as MR angiography and CT angiography, must be comparable to that of CCA if they are to be used as a substitute for CCA [9]. MR angiography can be performed together with CCA, but could not replace it. It was reported that when used to image brain AVMs, it could not show small vessels and regions of slow blood flow with the same degree [10].

Both modalities catheter based angiography and Computed tomographic angiography are used in diagnosis of cerebral arterial aneurysm and arteriovenous malformation. The (58\%) 29 patients with cerebral arterial aneurysm out of which (20\%) 10 female and (38\%) 19 male came with different ages from 3rd to 7th decade, which mean that the aneurysm develops in all ages and the majority in adult between 30 to 60 years. The (42\%) 21 patients with arteriovenous malformation out of which (14\%) 7 female and (28\%) 14 male came with ages from 2nd to 5th decade, as a result the AVM appear more in younger patients between 10 to 30 years [9]. 


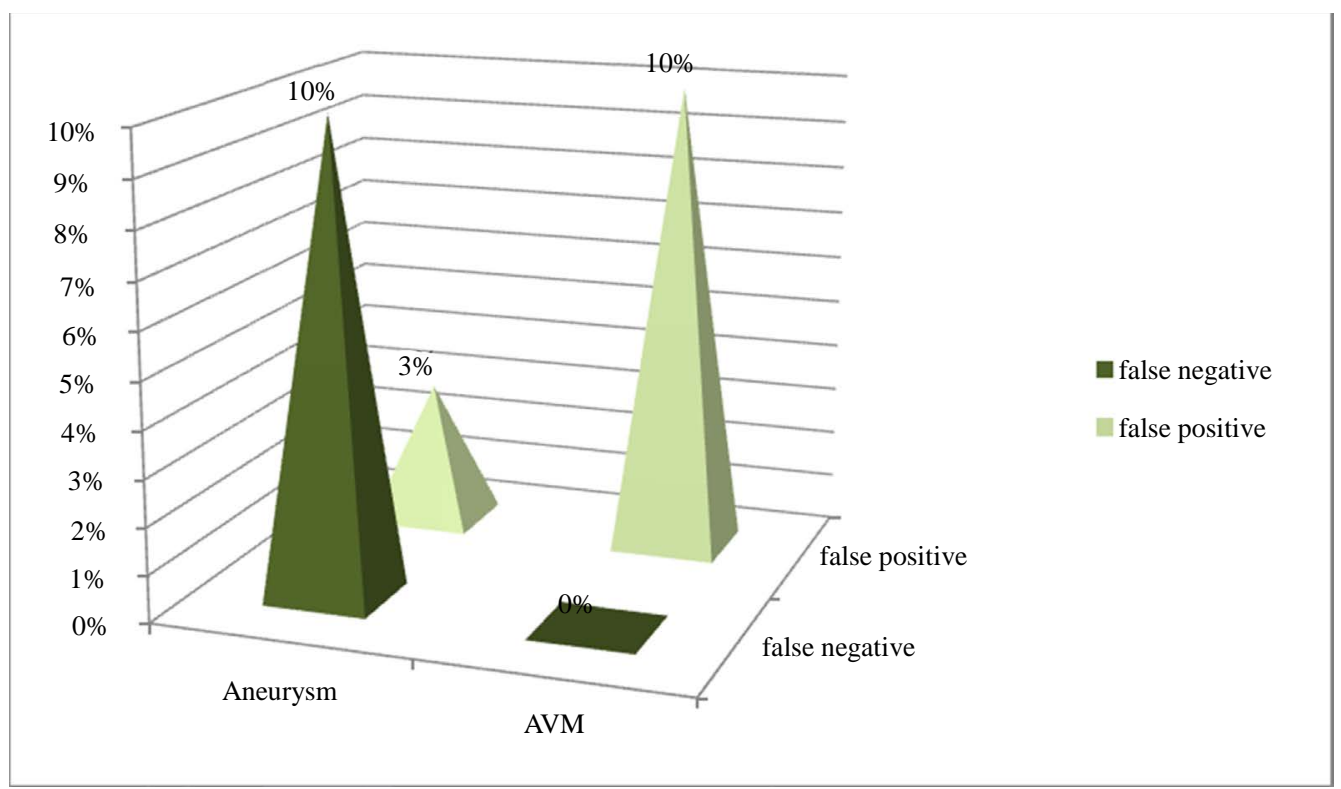

Figure 8. Percentage of false positive and negative in CTA.

Despite advances in noninvasive diagnostic neuroimaging, diagnostic cervicocerebral angiography remains the criterion standard for the evaluation of patients.

In catheter based angiography (97\%) 28 patients proved that they have cerebral aneurysm and (3\%) 1 patient was proved that he do not has aneurysm. In addition, 3 patients out of 4 with suspected aneurysm in CTA was proved by catheter based angiography that they have aneurysm and one with no aneurysm. Also 3 patients with no aneurysm in CTA were proved by catheter based angiography that they have a very small aneurysm less than $3 \mathrm{~mm}[9][11]$.

As a result, the sensitivity of CTA for picking up aneurysm is (86\%) 25 patients out of 29 and the specificity of CTA for picking up aneurysm is (76\%) 22 patients out of 29. The false positive cases were (3\%) one patient with suspected aneurysm in CTA and no aneurysm in catheter based angiography [12].

The false negative cases were (10\%) 3 patients with no aneurysm in CTA and proved by catheter based angiography that they have a very small aneurysm less than $3 \mathrm{~mm}$. The sensitivity and specificity of catheter based angiography for picking up aneurysm is (100\%) [3] [4].

In CTA (76\%) 16 of patients with suspected AVM was proved that they have arteriovenous malformation, (24\%) 5 patient with suspicion AVM and catheter based angiography is recommended for accurate assessment. In catheter based angiography (90\%) 19 patients was proved that they have AVM [12]. In addition, 3 patients out of 5 with suspected AVM in CTA was proved by catheter based angiography. The specificity of CTA for picking up AVM is (76\%) 16 patients out of 21. The false positive cases were (10\%) two patients with suspected AVM in CTA and no AVM in catheter based angiography. No false negative cases in CTA. The sensitivity and specificity of catheter based angiography for picking up AVM is (100\%) [4].

Previous study revealed that the accuracy, sensitivity, positive predictive accuracy and negative predictive accuracy for CTA was $98 \%, 97.9 \%, 100 \%$ and $94.3 \%$ and for DSA was $99 \%, 99.3 \%, 100 \%$ and $98 \%$, respectively. CTA is a reliable alternative to DSA in detecting intracranial aneurysms. The role of CTA in demonstrating AVMs can be considered complementary to that of DSA [13]. While the present study revealed that the specificity of CTA is $76 \%$ in diagnosis and detection of cerebral arterial aneurysm and arteriovenous malformation are $86 \%$ and $90 \%$ respectively, while the sensitivity and specificity of catheter based angiography is $100 \%$. However, in another earlier study, MDCTA sensitivity, specificity, and accuracy were $92.5 \%$, 93.3\%, and 92.6\%, respectively [14].

\section{Conclusion}

The present study concluded that CTA has high sensitivity and specificity in detecting aneurysm and AVM enough to be chosen as the first step. Catheter based angiography, still a gold standard radiology examination, is 
the most accurate, sensitive and specific method in diagnosis and detection of cerebral arterial aneurysm and arteriovenous malformation, which can be done as the second step. In addition, catheter based angiography is done for treatment planning, treatment with interventional procedure and for prognosis after treatment.

\section{References}

[1] Brown Jr., R.D., Wiebers, D.O., Torner, J.C. and O’Fallon, W.M. (1996) Frequency of Intracranial Hemorrhage as a Presenting Symptom and Subtype Analysis: A Population Based Study of Intracranial Vascular Malformations in Olmsted County, Minnesota. Journal of Neurosurgery, 85, 29-32. http://dx.doi.org/10.3171/jns.1996.85.1.0029

[2] Van Gijn, J., Kerr, R.S. and Rinkel G.J. (2007) Subarachnoid Haemorrhage. Lancet, 369, 306-318. http://dx.doi.org/10.1016/S0140-6736(07)60153-6

[3] Chow, L.C. and Rubin, G.D. (2002) CT Angiography of the Arterial System. Radiologic Clinics of North America, 40, 729-749.

[4] Goddard, A.J., Tan, G. and Becker, J. (2005) Computed Tomography Angiography for the Detection and Characterization of Intra-Cranial Aneurysms: Current Status. Clinical Radiology, 60, 1221-1236.

[5] Villablanca, J.P., Nael, K., Habibi, R., Nael, A, Laub, G. and Finn, J.P. (2006) 3T Contrast-Enhanced Magnetic Resonance Angiography for Evaluation of the Intracranial Arteries: Comparison with Time-of-Flight Magnetic Resonance Angiography and Multislice Computed Tomography Angiography. Investigative Radiology, 41, 799-805.

[6] Kato, K., Tomura, N., Takahashi, S., et al. (2003) Ischemic Lesions Related to Cerebral Angiography: Evaluation by Diffusion Weighted MR Imaging. Neuroradiology, 45, 39-43.

[7] Vaphiades, M.S. and Horton J.A. (2005) MRA or CTA, That's the Question. Survey of Ophthalmology, 50, 406-410.

[8] Yang, Y.J., Chen, W.J., Zhang, Y., Wu, Z.B., Zhong, M., Tan, X.X., et al. (2007) Diagnostic Value of CTA and MRA in Intracranial Traumatic Aneurysms. Chinese Journal of Traumatology, 10, 29-33.

[9] Cloft, H.J., Joseph, G.J. and Dion, J.E. (1999) Risk of Cerebral Angiography in Patients with Subarachnoid Hemorrhage, Cerebral Aneurysm, and Arteriovenous Malformation: A Meta-Analysis. Stroke, 30, 317-320. http://dx.doi.org/10.1161/01.STR.30.2.317

[10] Parker, D.L., Tsuruda, J.S., Goodrich, K.C., Alexander, A.L. and Buswell, H.R. (1998) Contrast-Enhanced Magnetic Resonance Angiography of Cerebral Arteries: A Review. Investigative Radiology, 33, 560-572. http://dx.doi.org/10.1097/00004424-199809000-00012

[11] Hahnel, S., Bender, J., Jansen, O., et al. (2001) Clinically Silent Cerebral Embolisms after Cerebral Catheter Angiography. Rofo, 173, 300-305

[12] Katzen, T.B. (2002) The Future of Catheter-Based Angiography: Implications for the Vascular Interventionalist. Radiologic Clinics of North America, 40, 689-692.

[13] Kokkinis, C., Vlychou, M., Zavras, G.M., Hadjigeorgiou, G.M., Papadimitriou, A. and Fezoulidis, I.V. (2008) The Role of 3D-Computed Tomography Angiography (3D-CTA) in Investigation of Spontaneous Subarachnoid Haemorrhage: Comparison with Digital Subtraction Angiography (DSA) and Surgical Findings. British Journal of Neurosurgery, 22, 71-78. http://dx.doi.org/10.1080/02688690701713862

[14] Yoon, D.Y., Lim, K.J., Choi, C.S., Cho B.M., Oh, S.M. and Chang, S.K. (2007) Detection and Characterization of Intracranial Aneurysms with 16-Channel Multidetector Row CT Angiography: A Prospective Comparison of VolumeRendered Images and Digital Subtraction Angiography. AJNR, 28, 60-67. 
Scientific Research Publishing (SCIRP) is one of the largest Open Access journal publishers. It is currently publishing more than 200 open access, online, peer-reviewed journals covering a wide range of academic disciplines. SCIRP serves the worldwide academic communities and contributes to the progress and application of science with its publication.

Other selected journals from SCIRP are listed as below. Submit your manuscript to us via either submit@scirp.org or Online Submission Portal.
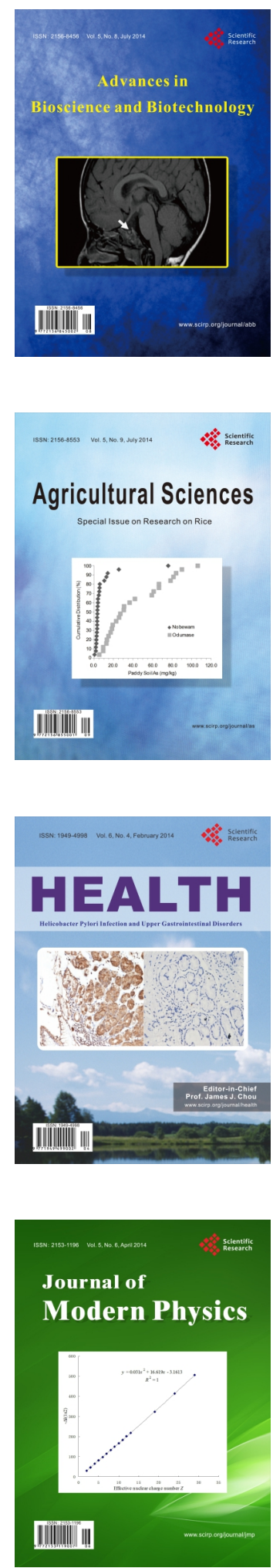
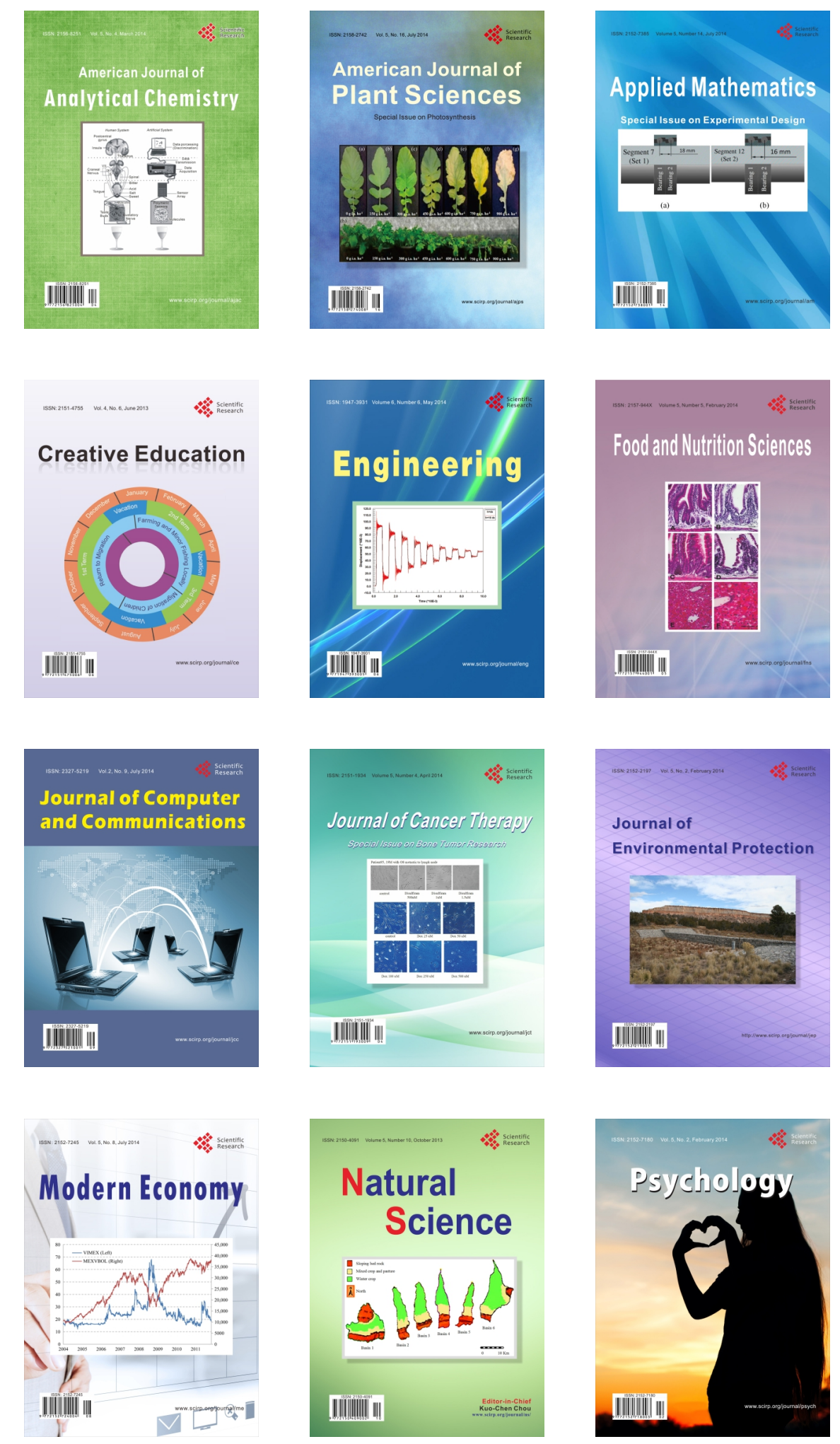